\title{
Performance Investigation of Refrigerant R-407C as a Replacement to Refrigerant R22 in Window Air Conditioner Unit
}

\author{
Ibrahim F. Abdulqadir ${ }^{1}$, Badran Salim², Omar M. Ali ${ }^{3, *}$ \\ ${ }^{1}$ Department of Energy Engineering, Technical College of Engineering, Duhok Polytechnic University, Iraq, \\ Ibrahim.fadilaldin@dpu.edu.krd \\ ${ }^{2}$ Department of Refrigeration and Air Conditioning, Technical College of Engineering, Northern Polytechnic University, \\ Iraq, badranm2015@gmail.com \\ ${ }^{3}$ Department of Mechanical Engineering, College of Engineering, University of Zakho, Iraq, omar.ali@uoz.edu.krd \\ *Correspondence: omar.ali@uoz.edu.krd
}

\begin{abstract}
The present work deal with the experimental study to retrofit the refrigerant $\mathbf{R} 407 \mathrm{c}$ with the refrigerant $\mathbf{R 2 2}$ in the air conditioning unit at an ambient temperature range between $30-45^{\circ} \mathrm{C}$. The main component of the experimental rig includes a window air conditioner with a refrigeration capacity of 2 Ton refrigeration that used refrigerant $R 22$ as a working fluid in the experimental work. The refrigerant $\mathrm{R} 22$ is replaced with refrigerant $\mathrm{R407C}$ due to similar operation properties for the two refrigerants. The experimental results displayed the refrigeration effect and coefficient of performance COP of the R22 system are high as with those of the R407C system. The falls in the evaporator and condenser for the R407C system is lower than that of the $R 22$ system. The temperature of discharge in the compressor for the system of refrigerant $R 22$ is greater than that of the $R 407 C$ system. Moreover, condensation temperature along the tube of the condenser is decreased with the increase of the distance for both refrigerants. The refrigerant $\mathbf{R 4 0 7 C}$ may be selected as a good alternate for $\mathrm{R22}$ with an agreement difference in the two refrigerants' performance. The system did not require replacement for any part of the AC unit.
\end{abstract}

Keywords: R22, Compressor Oil, Refrigeration Effect, COP, Refrigerant.

Received: November 16, 2020 / Accepted: December 30, 2020 / Online: December 31, 2020

\section{INTRODUCTION}

The refrigeration systems have important purpose in many applications that associated with human activity. There are various applications of the refrigeration system such as residential applications, manufacture processes, food conservation, transport and conservation, and human comfort [1]. The hydrochlorofluorocarbon refrigerant R22 have high GWP and ozone depletion, therefore, the protocol of Montreal 1987 decided to replace HCFCs refrigerants by 2030 in whole developed countries and by 2040 in the developing countries [2] and [3].

The HCFC refrigerants have excellent thermal and chemical properties, therefore, the refrigerants are employed in large broad of applications and refrigerant R22 is one of the significant HCFC refrigerants, which it is employed in a wide range of refrigeration and air conditioning applications [4]. In last years, the existing of suitable alternate refrigerants for R22 that are out of the phase and the performance investigation of the suitable alternative refrigerants as compared with refrigerant $\mathrm{R} 22$ are the major challenge for the researchers. Refrigerants R407C and R22 have common thermal properties, in addition of R407C safety properties, therefore, the refrigerant $\mathrm{R} 407 \mathrm{C}$ can be a good alternate of R22 [5].

There are many experimental and numerical studies deal with the investigation of refrigerant R22 in AC applications with safe refrigerants. Bolaji [6] experimentally study the thermal behaviors of refrigerants R404A and R507 as compared with R22 in a window AC. He finding that the pressure ratio and the compressor discharge temperature of the R507 and R404A respectively, were higher than those of R22 with percentages of $4.2 \%$ and $15.3 \%$. Devotta et al. [7] experimentally studied the thermal behavior of 1.5 Ton Refrigerant window AC using refrigerants R407C and R22. The findings showed that the refrigeration effect of refrigerant $\mathrm{R} 22$ system is larger than those for R407C with a variation between $2.1-7.9 \%$, the R22 coefficient of performance COP was higher than those for $\mathrm{R} 407 \mathrm{C}$ in the range of $7.9-13.5 \%$.

The evaporator and condenser pressure drop of R407C system are higher than those of R22 system. Devotta et al. [8] numerically studied the evaporation and condensation in a heat exchanger with refrigerants R22 and R407C using a software that built-in model. The results validated their previous experimental results [7]. Kaseraa et al. [9] previewed several studies deal with the performance of R22, R407C and R410A.

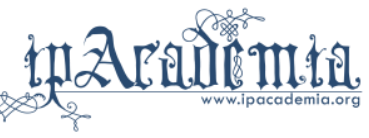


Most of the publications explained that the refrigerant R22 have better performance than that other refrigerants and the $\mathrm{R} 407 \mathrm{C}$ is selected as the suitable substitute instead of refrigerant R22 from the retrofitting field but the refrigerant R410A is more suited from the design view. Sharmas and Babu [2] investigated theoretically the vapor compression refrigeration system thermodynamic performance using ozone friendly mixtures of HC and HFC as a substitute refrigerant to substitute the refrigerant $\mathrm{R} 22$ with the condenser and evaporator temperatures of $54.4^{\circ} \mathrm{C}$ and $7.2^{\circ} \mathrm{C}$. The results displayed the mixture R134a/R1270/R290 (50/5/45 by mass percentage) have better thermodynamic performance than that of R22 with energy savings, therefore, it is suitable substitute refrigerant for $\mathrm{R} 22$ in $\mathrm{AC}$ applications.

Choudhari and Sapali [10] analyzed theoretically the possibilities of R290 as a replacement to R22 based on analytical calculations and the properties of refrigerants are obtained using the software REFPROP. The results displayed that the discharge temperature, volumetric refrigerating capacity and refrigerant charge are lower with R290 system as compared with those of R22 system. The R290 COP is slighter than those of R22 system. The authors verified that R290 be a good alternate to R22 in real refrigeration applications due to its very good environmental, thermal and physical properties.

Venkataiah and Rao [11] presented numerical results of a $5 \mathrm{~kW}$ room AC for different refrigerants that used as substitute refrigerants instead of R-22 in AC applications. The thermodynamic analysis of refrigerants R-22, R407C, R410A, R-134a, R507A, R404A, R290, and R600a is investigated using the software COOL PACK and a comparison is made. Venkataiah and Rao [12] are used the simulation results for a system include $1.5 \mathrm{TR}$ cooling capacity AC unit with different refrigerants that employed as replacement of R22 for AC applications. The zero Ozone depletion potential refrigerants are choosing in this study. The thermodynamic analysis of R22，R507A，R134a，R404A，R410A，R407C，R290 and $\mathrm{R} 600 \mathrm{a}$ refrigerants has been investigated using COOLPACK software. The results are obtained at fixed condenser temperature and variable evaporator temperatures. The results indicated that R290 and R600a require low refrigerant mass flow rate and R507 and R404A need large refrigerant mass flow rate, R600a required largest displacement volume of the compressor and R410A required smallest displacement volume of the compressor.

The basic vapor compression refrigeration systems and its improvements with different application using various refrigerants are studied and reviewed by some authors. The investigations are used R22 and its replacements, Agrawal, Patil and Nandab [13], Bedoić and Filipan [14], Mahmood, Ali and Noor [15], Park et. al. [16], Minh, Hewitt and Eames [17], Mohanraj, Muraleedharan and Jayaraj [18], Mahmood, Buttsworth and Malpress [19], Fatouh, Ibrahim and Mostafa [20], Shaik and Babu [21] and Mahmood, Buttsworth and Malpress [22].

The most previous studies deal with experimental and theoretical investigation to find out the substitute refrigerants to replace R22 using split air conditioner with cooling capacity of 1-1.5 TR and specific ambient temperature.

The present paper includes an experimental study to investigate the performance of window $\mathrm{AC}$ with evaporator load capacity of 2 TR and different ambient conditions using $\mathrm{R} 22$ and $\mathrm{R} 407 \mathrm{C}$ as refrigerants. The type of the compressor is a rotary hermetic. The study includes the comparison of the cooling capacity, work of compressor, coefficient of performance and pressure drop in the evaporator and condenser, and the influence of the ambient temperature on $\mathrm{R} 22$ and R407C systems to prove that the R407C be the suitable replacement of R22 for the system.

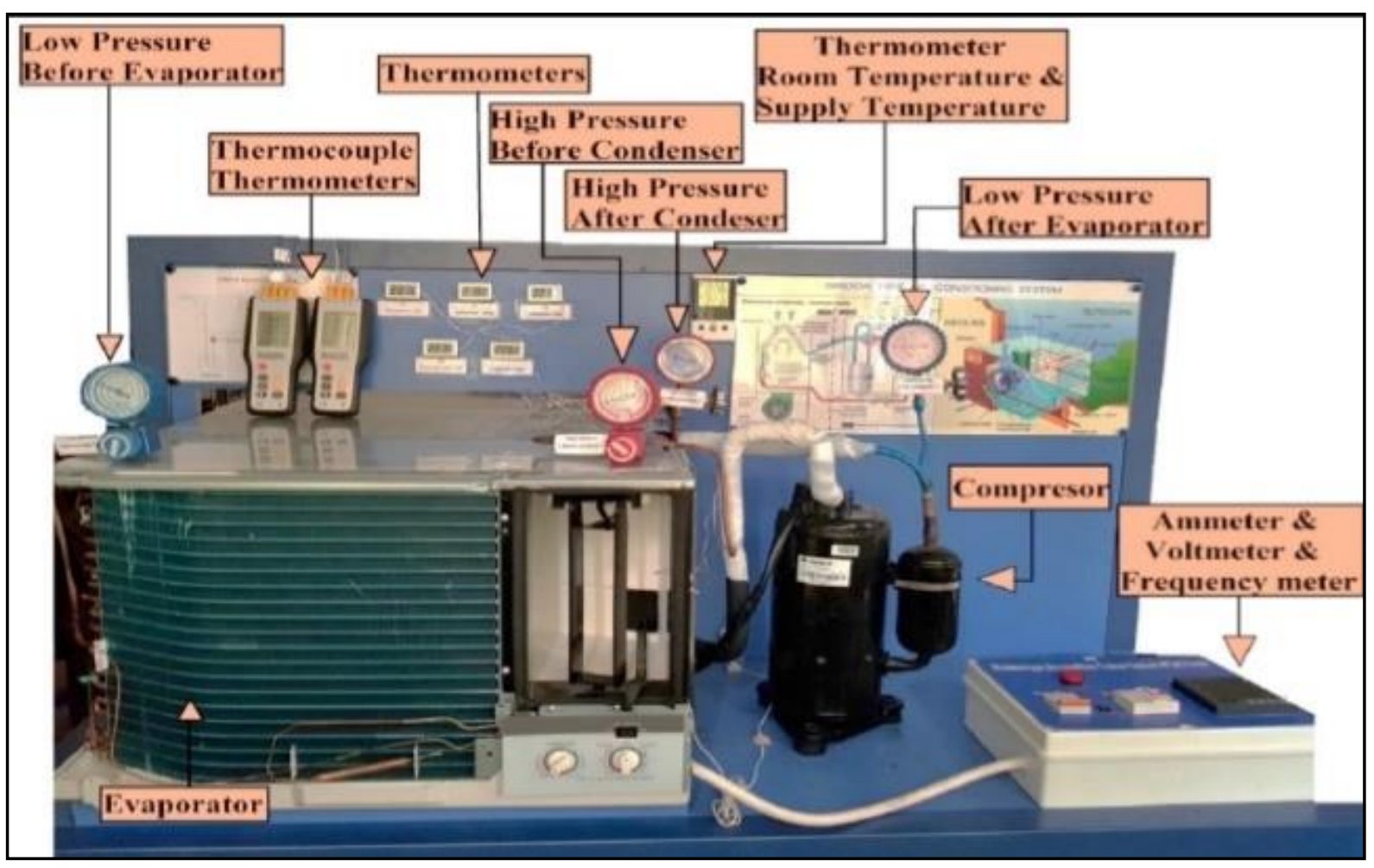

Fig. 1. Main Parts of Window Air Conditioner 


\section{EXPERIMENTAL SETUP}

The schematic diagrams of the experimental setup for the present study are illustrated in Fig.1 and Fig.2. The experimental rig include window air conditioner with main four parts; rotary compressor, forced finned tube condenser, capillary tube as expansion valve and forced finned tube evaporator. In An auxiliary window AC nit is used to control the temperature that surrounded the condenser, Fig. 2. The pressures, temperatures, and electrical data at different locations of the system are measured using pressure gauges, thermometers (thermocouples), and Multimeter.

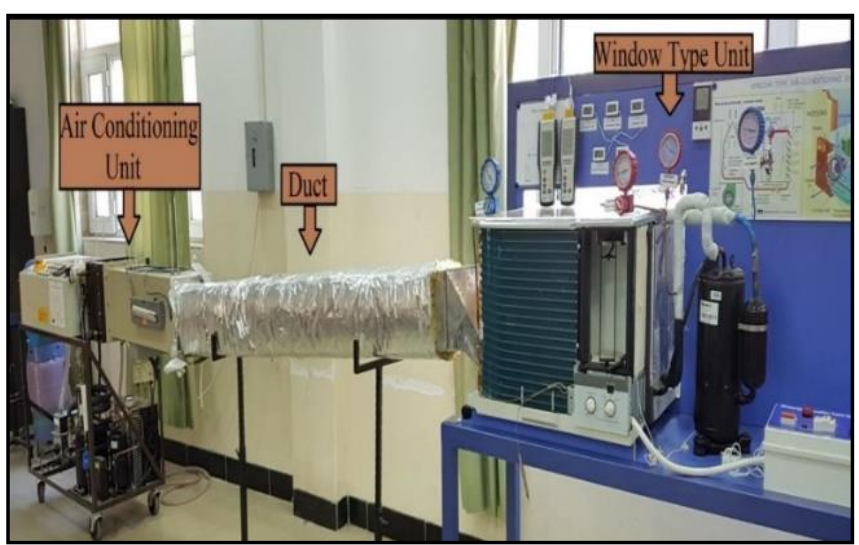

Fig. 2. All Parts of Experimental

High, low pressures and pressure drop in the evaporator and condenser in the system are measured using four pressure gages. The temperatures of the refrigerant are recorded using thermocouples at different locations that installed on the connection lines. Seven temperature measurements (thermocouples) are installed along the tube of the condenser to measure the temperature distribution along the condenser tube. Multimeter is used to measure the current and voltage readings of the compressor and the frequency meter is used to measure the frequency of the compressor. The whole system is operated using R22 as refrigerant and the data is collected at various operation conditions. The refrigerant R22 is replaced with $\mathrm{R} 407 \mathrm{C}$ as substitute refrigerant, the compressor oil replaced using suitable oil for R407C. The test process consists of the following steps for both refrigerants:The main window $\mathrm{AC}$ unit in the experimental rig is operated and the fluid is circulated in the refrigeration cycle.

1. The other parts of the system are operated and the temperature of the air surrounded the condenser is specified at the desired temperature.

2. The measurement data are recorded when the whole system is reached to the steady state operation.

3. The ambient temperature is changed to other temperature the procedure is repeated.

\section{DATA REDUCTION}

The performance data are calculated in the cycle, fig. 3, which is assumed as an ideal cycle and it consist of the following processes:

1-2: Compression, Isentropic process in compressor, $\mathrm{s}_{2}=\mathrm{s}_{1}$ 2-3: constant pressure process with heat extraction in the condenser
3-4: Throttling process in the capillary tube, $\mathrm{h}_{3}=\mathrm{h}_{4}$. 4-1: constant pressure process with heat absorption in the evaporator.

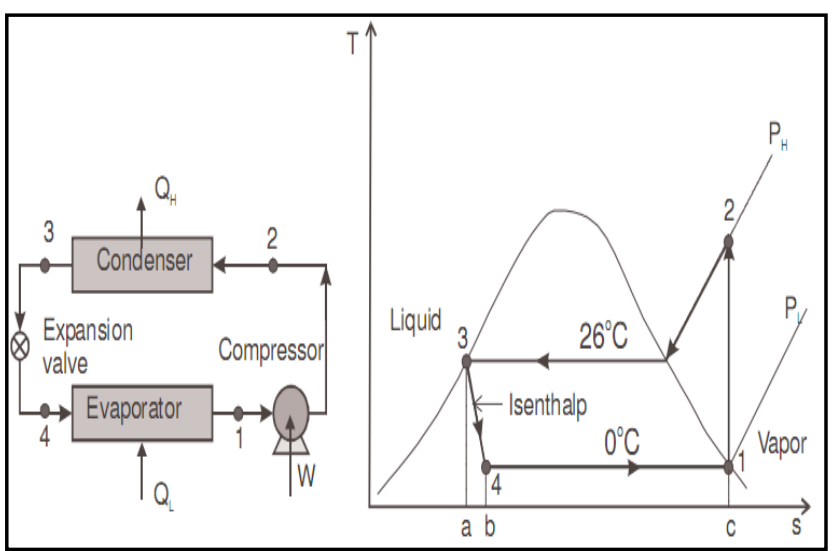

Fig. 3. Refrigeration system and T-s diagram from:

The refrigeration effect in the evaporator is determined

$W_{c}=h_{1}-h_{4}$

Where $h_{1}$ represent the enthalpy at the entrance of the compressor at evaporator pressure, $\mathrm{kJ} / \mathrm{kg}$.

$\mathrm{h}_{4}$ represent the enthalpy at the inlet of the evaporator at evaporator pressure, $\mathrm{kJ} / \mathrm{kg}$.

The work added by the compressor, $\mathrm{kJ} / \mathrm{kg}$ is

$W_{c}=h_{2}-h_{1}$

Where $h_{2}$ represent the enthalpy at the exit of the compressor at condenser pressure, $\mathrm{kJ} / \mathrm{kg}$.

The COP of the refrigeration cycle as follow:

$$
\text { COP }=\frac{\text { Refrigeration Effect }}{\text { Work Doone }}
$$

\section{VALIDATION OF THE PRESENT WORK}

To verify the present work, the results of the COP for present work is compared with the previous experimental work [7] that used a window air conditioner with cooling capacity of 1.5 TR for two ambient temperatures using R22 as refrigerant as displayed in table $\mathrm{I}$.

TABLE I. COMPARISON BETWEEN PRESENT WORK AND PREVIOUS WORK [7]

\begin{tabular}{|c|c|c|}
\hline $\mathbf{T}_{\text {amb. }}{ }^{\circ} \mathbf{C}$ & Present work & Previous work \\
\hline 35 & 3 & 2.45 \\
\hline 45 & 2.5 & 1.95 \\
\hline
\end{tabular}

The trends of the present results and previous data are similar, but the agreement in the values have a deviation due to the variation in the cooling capacity for two systems ( 2 TR for present work and 1.5 TR for previous work).

\section{V.RESULTS AND DISCUSSION}

The study is an experimental analysis to compare the thermal and physical behaviors of a window air conditioner unit using R407C with those of refrigerant R22. The 
performance of the systems using R22 and R407C refrigerants are estimated under different ambient temperatures with values $30,35,40$ and $45^{\circ} \mathrm{C}$ to test that the refrigerant $\mathrm{R} 407 \mathrm{C}$ be a suitable replacement for refrigerant R22. Figs. 4-8 represent the influence of the ambient temperature variation on the performance parameters in two refrigerant systems.

The variation of the compressor work with ambient temperature is displayed in Fig. 4. As the ambient temperature is increased, the compressor work increased for R22 and R407C systems because the evaporator and condenser temperatures are increased. An increase in the ambient temperature led to add extra load on the compressor motor, therefore, the compressor motor is operated longer time until reaching the desired set point of the system. The increase of compressor work for R407C system is higher than those for R22 system because the evaporation and condensation of R407C system are higher than those of R22 system under similar environment temperature. The maximum variation in the added work between two systems reaches to $22 \%$ at ambient temperature $30^{\circ} \mathrm{C}$.

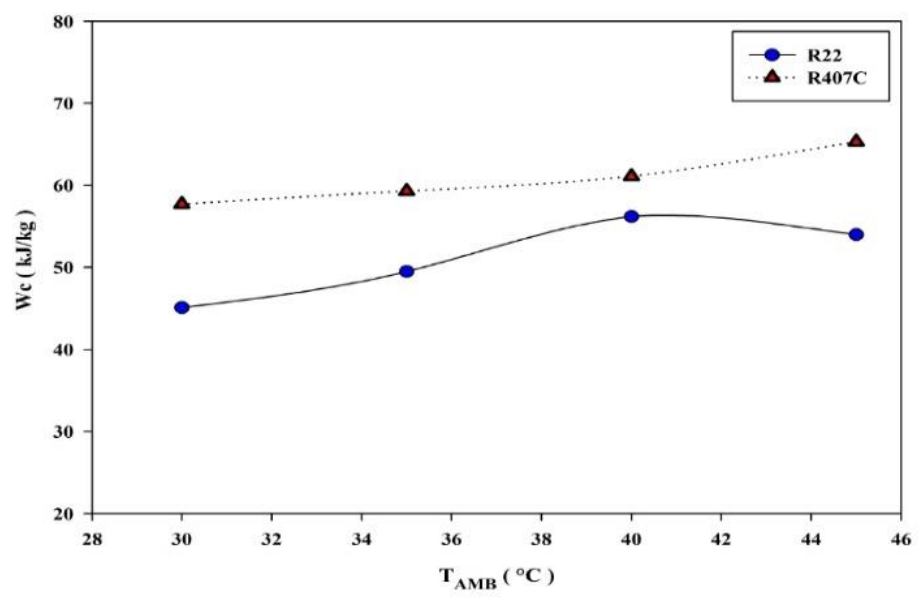

Fig. 4. Compressor Work of R22 and R407C systems

Fig. 5 displays the influence of the environment temperature variation on the refrigeration effect for two refrigerants. The refrigeration effect RE of R22 and R407C systems decreases with the increase of the ambient temperature. The cooling effect for R22 system is greater than that of R407C system with similar operation conditions due to small variation in thermal properties for two refrigerants R22 and $\mathrm{R} 407 \mathrm{C}$. The greatest variation in the RE between both systems is about $5 \%$ at ambient temperature $30^{\circ} \mathrm{C}$.

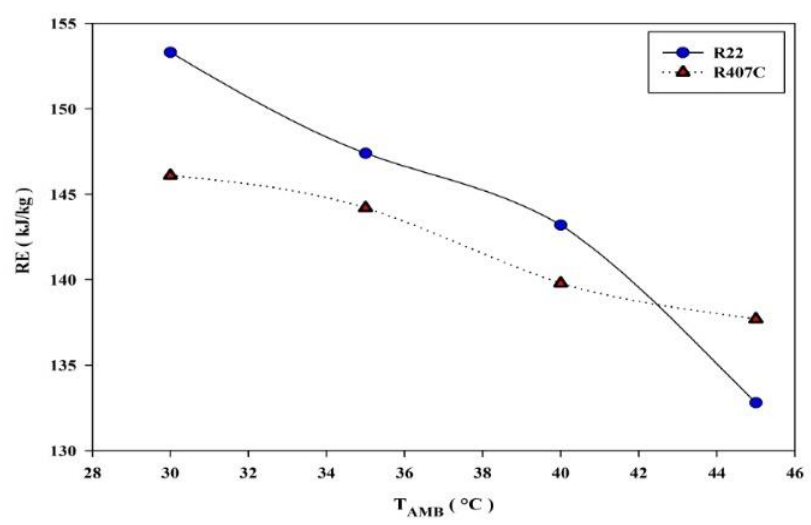

Fig. 5. Refrigeration Effect of R22 and R407C systems
The COP variation with its environment temperatures is shown in Fig. 6. As the ambient temperature is increased, COP is decreased for R22 and R407C systems. There is a large difference between COP of two systems at some ambient temperatures. The greatest COP difference is obtained at $30^{\circ} \mathrm{C}$ with a percentage reached to $26 \%$.

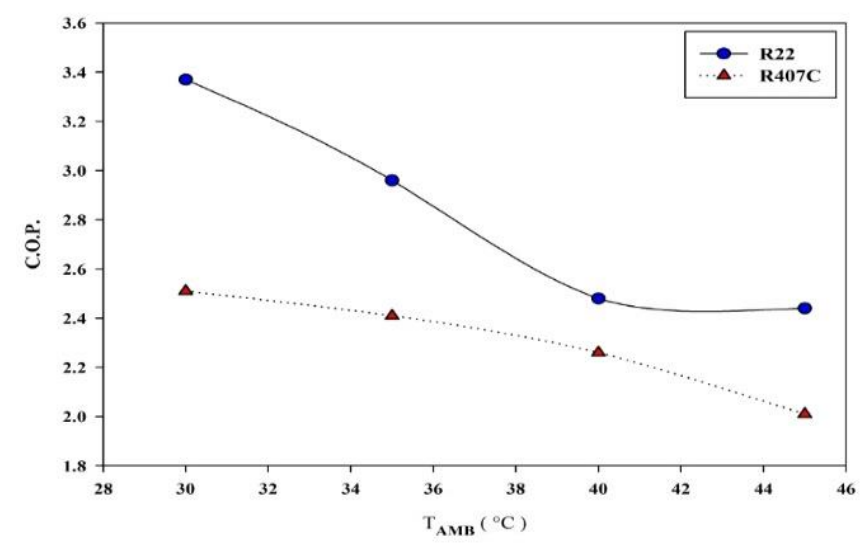

Fig. 6. COP of R22 and R407C Systems

Fig. 7 shows the pressure drop in the condenser for R22 and $\mathrm{R} 407 \mathrm{C}$ systems with variable ambient temperatures. The condenser pressure drop for both refrigerants is different at $30^{\circ} \mathrm{C}$ and $45^{\circ} \mathrm{C}$, while, the pressure drop have similar values for other temperatures.

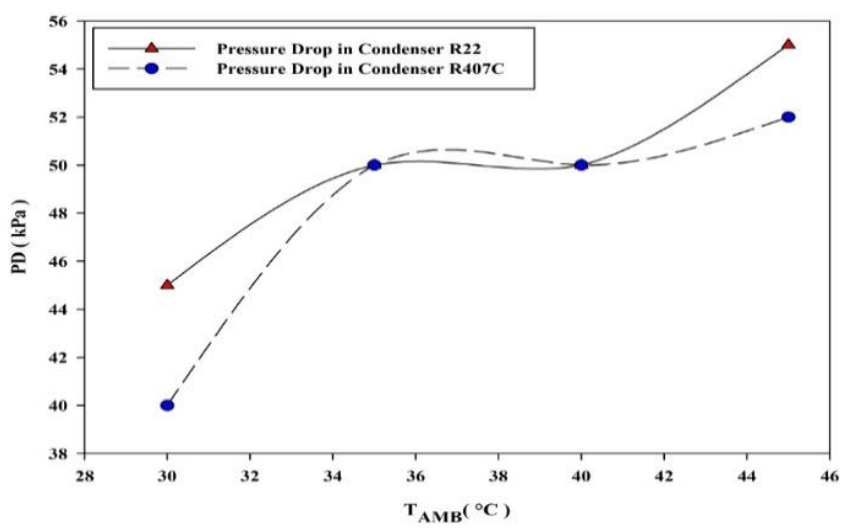

Fig. 7. Pressure Drop within Condenser for R22 and R407C

The evaporator pressure drop for two refrigerants is influenced by the ambient temperature, Fig. 8. The evaporator pressure drop of the system that uses R22 is greater than that for R407C with same operation conditions. The maximum difference of the evaporator pressure drop is achieved at $40^{\circ} \mathrm{C}$, while the pressure drops for both refrigerants are equal at $45^{\circ} \mathrm{C}$. 


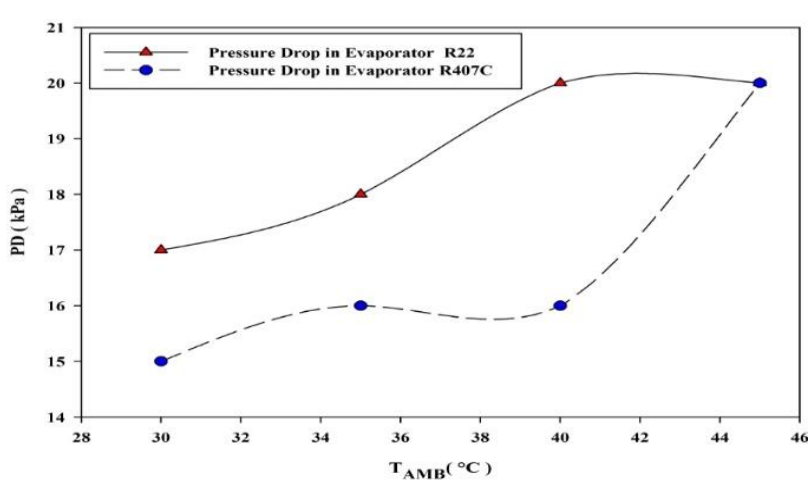

Fig. 8. Pressure Drop within Evaporator for R22 and R407C

The condensation temperature distribution along the condenser tube for R22 and R407C systems for 30 and $45^{\circ} \mathrm{C}$ are shown in Fig. 9. The results displayed that, the increase in the distance, the condensation temperature is decreased for two refrigerant systems. The increase in the ambient temperature led to an increase in the condensation temperature because of shortage in heat reject from the condenser.

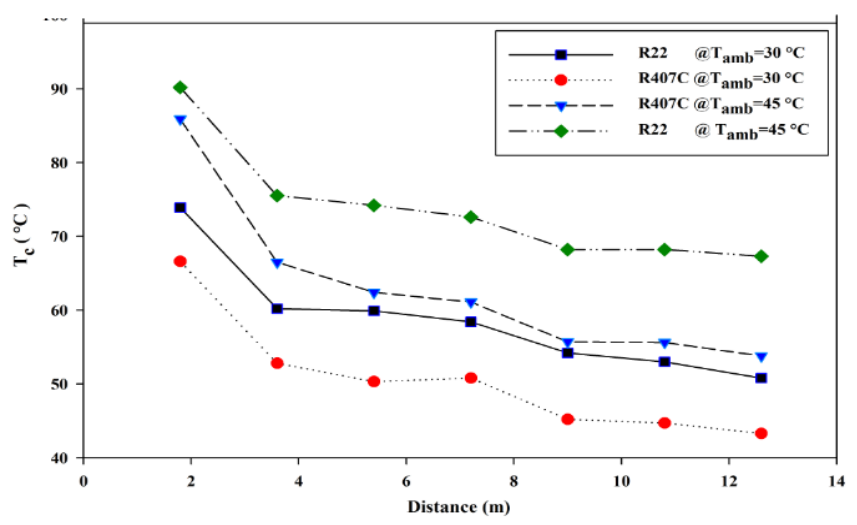

Fig. 9. Condensation Temperature for R22 and R407C Vs Distance

\section{CONCLUSIONS}

The retrofitting process of $2 \mathrm{TR}$ window $\mathrm{AC}$ unit using $\mathrm{R} 22$ as a refrigerant fluid with its replacement $\mathrm{R} 407 \mathrm{C}$ requires the comparison of performance between two refrigernats. The following conclusions from the investigation are illustrated:

1. The refrigerant is charged into the system without making any difference in the system except the compressor oil is changed.

2. The greatest difference in refrigeration effect for $\mathrm{R} 22$ and $\mathrm{R} 407 \mathrm{C}$ systems is reached to about $5 \%$.

3. The COP of R22 system is greater than those of R407C system with fair difference values, only there is a large difference at ambient temperature $30^{\circ} \mathrm{C}$.

4. The R22 system discharge temperature is larger than those for the R407C system.

5. The evaporator and condenser pressure drops for R407C system are lower than those of R22 system.

6. The condensation temperature along the tube of the condenser is decreased as the distance is increased for both refrigerants. The R407C system condensation temperature is greater than that for R22 system at all conditions.

7. The R-407C may be selected as a good alternative to retrofit R-22 due to the R-22 will be phased out.

\section{REFERENCES}

[1] Stoecker and Jones_Refrigeration and Air Conditioning $2^{\text {nd }}$ Ed McGraw Hill.

[2] S. V. Shaik and T. P. A. Babu, "Theoretical Performance Investigation of Vapour Compression Refrigeration System Using HFC and HC Refrigerant Mixtures as Alternatives to Replace R22," Energy Procedia, vol. 109, no. November 2016, pp. 235-242, 2017, doi: 10.1016/j.egypro.2017.03.053.

[3] "Montreal protocol on substances that deplete the Ozone layer final act 1987," J. Environ. Law, vol. 1, no. 1, pp. 128-136, 1989, doi: 10.1093/jel/1.1.128.

[4] I. F. Abdulqadir, B. M. Salim, and O. M. Ali, "Experimental Investigation to Retrofit HCFC-22 Window Air Conditioner with R407C," 2019, doi: 10.1109/ICOASE.2019.8723862.

[5] E. W. Lemmon, M. L. Huber, and M. O. Mclinden, "NIST Standard Reference Database 23: Reference Fluid Thermodynamic and Transport Properties-REFPROP, Version 9.1, Standard Reference Data Program," Natl. Inst. Stand. Technol. Gaithersburg, MD, pp. 1-3, 2013.

[6] B. O. Bolaji, "Performance investigation of ozone-friendly R404A and R507 refrigerants as alternatives to R22 in a window air-conditioner," Energy Build., vol. 43, no. 11, pp. 3139-3143, 2011, doi: 10.1016/j.enbuild.2011.08.011.

[7] S. Devotta, A. S. Padalkar, and N. K. Sane, "Performance assessment of HCFC-22 window air conditioner retrofitted with R-407C," Appl. Therm. Eng., vol. 25, no. 17-18, pp. 2937-2949, 2005, doi: 10.1016/j.applthermaleng.2005.03.002.

[8] S. Devotta, "Experimental Performance Assessment Of A Retrofitted Window Air Conditioner With R-407C,” 2002.

[9] S. Kasera and S. C. Bhaduri, "Performance of R407C as an Alternate to R22: A Review," Energy Procedia, vol. 109, pp. 4-10, 2017, doi: 10.1016/j.egypro.2017.03.032.

[10] C. S. Choudhari and S. N. Sapali, "Performance Investigation of Natural Refrigerant R290 as a Substitute to R22 in Refrigeration Systems," Energy Procedia, vol. 109, no. November 2016, pp. 346352, 2017, doi: 10.1016/j.egypro.2017.03.084.

[11] S. Venkataiah and G. V. Rao, "A Comparative Study of the Performance Characteristics of Alternative Refrigerants to R-22 in Room Air-conditioners," vol. 6, no. 3, pp. 333-343, 2013.

[12] S. Venkataiah and G. V. Rao, "Analysis of Alternative Refrigerants to R22 for Air-Conditioning Applications at Various Evaporating Temperatures," vol. 4, no. 3, pp. 39-46, 2014.

[13] N. Agrawal, S. Patil, and P. Nanda, "Experimental Studies of a Domestic Refrigerator Using R290/R600a Zeotropic Blends," Energy Procedia, vol. 109, no. November 2016, pp. 425-430, 2017, doi: 10.1016/j.egypro.2017.03.051.

[14] R. Bedoic and V. Filipan, "Heating performance analysis of a geothermal heat pump working with different zeotropic and azeotropic mixtures," J. Sustain. Dev. Energy, Water Environ. Syst., vol. 6, no. 2, pp. 240-253, 2018, doi: 10.13044/j.sdewes.d5.0189.

[15] R. A. Mahmood, O. M. Ali, and M. M. Noor, "Mechanical Vapour Compression Refrigeration System, Review Part 1: Environmental Challenge.," Int. J. Appl. Mech. Eng., vol. 25, no. 4, pp. 130-147, 2020, doi: 10.2478/ijame-2020-0054.

[16] C. Park, H. Lee, Y. Hwang, and R. Radermacher, "Recent advances in vapor compression cycle technologies," Int. J. Refrig., vol. 60, pp. 118-134, 2015, doi: 10.1016/j.ijrefrig.2015.08.005.

[17] N. Minh, N. Hewitt, and P. Eames, "Improved Vapour Compression Refrigeration Cycles: Literature Review and Their Application to Heat Pumps,” Int. Refrig. Air Cond. Conf. Purdue, pp. 1-8, 2006, [Online]. Available: http://docs.lib.purdue.edu/cgi/viewcontent.cgi?article=1794\&context =iracc. 
[18] J. Sarkar and S. Bhattacharyya, "Application of graphene and graphene-based materials in clean energy-related devices Minghui," Arch. Thermodyn., vol. 33, no. 4, pp. 23-40, 2012, doi: 10.1002/er.

[19] R. A. Mahmood, D. Buttsworth, and R. Malpress, "Computational and Experimental Investigation of using an Extractor in a Vertical Gravitational Flash Tank Separator," Int. J. Automot. Mech. Eng., vol. 16, no. 2, pp. 1689-1699, 2019.

[20] M. Fatouh, T. A. Ibrahim, and A. Mostafa, "Performance assessment of a direct expansion air conditioner working with R407C as an R22 alternative," Appl. Therm. Eng., vol. 30, no. 2-3, pp. 127-133, 2010, doi: 10.1016/j.applthermaleng.2009.07.009.
[21] S. V. Shaik and T. P. A. Babu, "Theoretical Computation of Performance of Sustainable Energy Efficient R22 Alternatives for Residential Air Conditioners," Energy Procedia, vol. 138, no. October, pp. 710-716, 2017, doi: 10.1016/j.egypro.2017.10.205.

[22] R. Mahmood and R. Buttsworth, David Malpress, "Computational and Experimental Investigation of the Vertical Flash Tank Separator Part 1: Effect of Parameters on Separation Efficiency," Int. J. AirConditioning Refrig., vol. 27, no. 1, 2019, doi: https://doi.org/10.1142/S2010132519500056. 